\title{
Strategic planning for development and conservation and the roles of citizens
}

\begin{abstract}
Strategic Development Planning goes back several decades in North America at municipal and regional municipality levels. Much of the earlier experience involved professionals and in particular consultants working frequently in the context of consulting companies. Citizens were often invited to attend one or more public meetings so that their opinions could be heard. In many situations however, it became clear that there was a need for a broader implication of citizens in the Strategic Development Planning process. Especially from the 1980s onwards, more and more of these processes involved a much larger mobilization of citizens and the recognition that it was not just a case of citizens being consulted, but rather that citizens could also take on roles of undertaking and managing action, even to the point of mobilizing the necessary resources upon which specific actions and projects could draw upon. In this short article, the key components of strategic development planning are first presented and described, followed by a discussion of the potential roles of citizens. It is argued that while it has become common in the last 30 years to talk about the multi-functionality of agricultural land, it is now becoming more and more common for discussions about the environment also to be regarded as multi-functional. Thus, environmental issues related to various issues such as water quality, conservation of wildlife, protection of heritage landscapes and so forth, can be associated with different territories, where some are primarily agricultural, others can be forested areas, and so forth; in each case, the environmental issues can become major especially in relation to agriculturally-oriented territories. These issues can be looked at as reflecting multiple functions or, in other words, multiple eco-systemic services. This multiplicity of issues and functions or services represents a major way of mobilizing citizens many of whom are very concerned about what can happen to these other functions or ecosystemic services; they can thus be used to increase the mobilization of citizens to participate in the processes of strategic development planning.
\end{abstract}

Keywords: strategic development planning, strategic orientations, environment, eco-systemic services, multi-functionality of different types of land or territories, citizen involvement of many kinds
Volume 3 Issue I - 2018

\author{
CR Bryant,' Bousbaine AD, ${ }^{2}$ Akkari $C^{\prime}$ \\ 'University of Montreal, Canada \\ 2University of Liege, Belgium
}

\begin{abstract}
Correspondence: Christopher Bryant, Department of Geography, School of Environmental Design, University of Montreal, Canada, Tel 226-337-37I2,

Email christopher.robin.bryant@gmail.com
\end{abstract}

Received: February 12, 2017 | Published: February 20, 2018

\section{Introduction}

Strategic Planning for Development, including the Conservation of Different Dimensions of the Environment, has increasingly involved citizens, not simply to have their opinions but also to become involved in the planning process and in the initiation and management of different types of projects aimed at achieving the objectives of different Strategic Orientations identified in the Strategic Development Plan for a territory (which at the local and regional level can be a municipality or a regional municipality or a territory within a municipality or regional municipality).

In this short article, first some key points about Strategic Development Planning are identified and briefly discussed. Second, the roles of citizens (as opposed to political actors and professional actors at local and regional levels) are identified; these roles for citizens are becoming recognized in many types of actions intended to improve a situation for a community. Third, the emphasis in this article regarding the roles of citizens in the development of plans for Strategic Orientations that deal with different types of environmental conservation is developed by using the notion of multi-functionality (a notion already developed very much in relation to agricultural development plans in some countries and territories), and specifically on the role of eco-systemic functions (or eco-systemic services) as a tool for mobilizing the participation of citizens because of the increasing interest in these services by more and more citizens in countries such as Canada and many European countries. Furthermore, when eco-systems are concerned, citizens as human beings are naturally part of eco-systems and so it is normal that they be involved. Finally the stage involving the process of monitoring and evaluation is presented and briefly discussed.

\section{Key Components of strategic development planning}

The basic components of a Strategic Development Plan and the process leading to the construction of such a plan have been identified in other publications ${ }^{1-4}$ so they are briefly presented in the first section of this article.

For a given territory, the first step in a strategic development plan is to identify the Vision for the community or territory. This Vision is usually multi-facetted simply because there are almost inevitably multiple orientations in the territory that can contribute to the Vision created by the citizens and other involved actors. Inevitably, many actors including citizens have their own personal interests which influence them, which is why it is essential for the participants to engage in discussions to reach a consensus. Since strategic development planning is a process, it is quite possible that the Vision 
might be modified and revised at later stages in the process, and this is frequently the case.

Strategic Orientations (SOs) represent the different sets of actions associated with each $\mathrm{SO}$ which can help move the territory closer to the Vision. Different types of Strategic Orientations exist (Sectoral Orientations (e.g. Agriculture, Tourism; Geographic Orientations (e.g. a watershed, a forested area, a flood plain, an industrial zone), and Thematic Orientations (e.g. communications, poverty, education). ${ }^{1}$ Each Strategic Orientation identified by citizens and other actors are then analyzed and a specific set of objectives discussed and associated with each SO. It is also important to recognize that some SO's overlap with other SO's to a certain extent (e.g. agriculture and environmental conversation... the maintenance of particular types of landscapes such as "humanized landscape and the conservation of biodiversity. ${ }^{5-7}$

Actions or Projects are the means by which the objectives can be achieved. In the type of strategic development being discussed in this article, actions and projects can be identified in the context of meeting the objectives of each SO. Citizens can take the lead and can even mobilize other actors to participate as well as even mobilizing the resources necessary to undertake the action or project, including financial resources. Frequently it is projects initiated by citizens which meet with true 'success'.

A final stage which is essential is the putting in place of a Continual Process of Monitoring and Evaluation both for the whole Strategic Development Plan as well as for each of the Strategic Orientations. In this process of monitoring and evaluation citizens have a major role to play although there is still much improvement needed.

\section{The roles of citizens in the process of strategic development planning}

In many Strategic Planning Processes, citizens have been involved largely via consultation processes and their opinions and perspectives simply asked for through discussions. However, many citizens have a considerable capacity to understand much of what happens in a territory and are also capable of identifying pertinent projects (actions) to help achieve the objectives set for each SO, and even to manage actions and projects and help find appropriate financing where necessary. $2,3,9$ It is important that citizens be communicated with and mobilized to participate in a fundamentally realistic manner, ${ }^{3,89}$ including in the processes of monitoring and evaluation of progress, both overall and for each SO. In some circumstances, teams of citizens have also been created and trained to manage the whole process of strategic development planning (e.g. some of the early projects initiated by the Federation of Canadian Municipalities in the late 1980's). ${ }^{11}$

\section{The multi-functionality of environmental types of strategic orientations}

The multiple functions that specific territories can support were known initially as 'multi-purpose use' in the U.S.A. and later became known starting in Western Europe as multi-functionality. ${ }^{12}$ Examples include: a) agricultural land which supports landscapes which can be highly valued by citizens and tourists, and b) agricultural development and conservation of water quality. This multifunctionality is particularly emphasized for strategic orientations that involve the conservation of different dimensions of the environment, such as wildlife, ecologically valuable territories, water quality and even the function of rural tourism. This multi-functionality is very much linked therefore to the multiplicity of Eco-System Services. ${ }^{13}$
Many of these functions or Eco-System Services can involve certain professionals but because of the needs of everyday life and the values many citizens attach to the environment in its broadest sense, citizens can be mobilized and integrated into teams for undertaking actions or projects, for instance, to improve water quality, to protect wildlife while at the same time as supporting the appropriate development of agriculture.

\section{Conclusion}

The multi-functionality and particularly the multiple Eco-System Services can be used to mobilize a substantial portion of the population to get citizens to become more and more involved in a planning process which deals with so many functions and Eco-System Services which are of substantial significance to the territory, municipality or regional municipality. Recognizing the values that many citizens in countries such as Canada place on these functions and Eco-System Services facilitates the mobilization of citizens to become involved in the strategic development process; the mobilization process is naturally based on effective communication processes, ${ }^{2,3}$ dealing with the different interests of different segments of the population as well an understanding of how best to communicate with different segments of the population. Despite the substantial progress that has been made in this relatively novel strategic planning process, there remains major challenges. First, one challenge relates to the way in which local and regional governments and their professional planners view what is in effect a process of sharing their tasks with citizens and other actors who are not part of the local and regional governments, and as well it is not uncommon for political actors to have an incorrect vision of reality. A second major challenge is the lack of monitoring and evaluation, the fifth stage of strategic development planning, which will save time and money. When a development plan does not include this important stage, not only can it easily fail but it can take so much time for failure to be recognized. Ideally, strategic development planning needs to employ two approaches incrementally and simultaneously, an adaptive management approach and a holistic approach, both of which can be very important in enhancing the resilience for communities and their territories. ${ }^{14}$

\section{Acknowledgements}

None.

\section{Conflict of interest}

The author declares no conflict of interest.

\section{References}

1. Bousbaine AD, Akkari C, Bryant CR. Strategic Development Planning for Agricultural Development and the Integration of other Domains Important for the Territory. Int J Avian \& Wildlife Biol. 2017;2(6):1-9.

2. Bryant CR. Representation and Segmentation: The Strategic Management and Planning of Sustainable Community Development. In: Bryant CR, Marois C, editors. Proceedings of the $1^{\text {st }}$ Colloquium of the International Geographic Union (IGU) Commission on The Sustainable Development of Rural Systems. Canada: Department of Geography, University of Montréal; 1995. p. 179-189.

3. Bryant CR. Mobilizing and Planning the Community's Strategic Orientations: Basic Tips. Canada: Sustainable Community Analysis Workbook 4, St Eugène, Econotrends Ltd; 1995.

4. Bryant CR, Preston RE. Strategic Economic Planning and Local Development. Economic Development Bulletin. 1987;2:1-17. 
5. Bryant CR, Courcier S, Domon G. The maintenance of activities, The Humanized Landscape in Quebec. In: Domon G, editor. Canada: The Presses of the University of Montreal; 2009. p. 95-133.

6. Trépanier MO, Bryant CR. Principles of Management and Organization, the Humanized Landscape in Quebec, Montréal. In: Domon G, editor Canada: The Presses of the University of Montreal; 2009. p. 211-233.

7. Bryant CR, Granjon D. Sustainability of Rural Systems by Integrating with Urban Systems through Strategic Planning for Local Development in the Rural Urban Fringe. In: Epps R, editor. sustainable Rural Systems: Proceedings of the $1^{\text {st }}$ Annual Colloquium of the International Geographic Union (IGU) Commission on the Sustainability of Rural Systems. Australia; 1998. p. 205-214.

8. Bousbaine AD, Bryant CR. Innovative alternative agri-food systems: a case study on the Liege Food-Land Belt. Belgeo: Belgian journal of geography. 2017;2:1-19.

9. Bryant CR. Community-based Strategic Planning, Mobilisation and Action at the Edge of the Urban Field: The Case of Haliburton County, In: Bowler I, Bryant CR, et al. editors. Progress in Research on Sustainable Rural Systems. Portugal: New University of Lisbon, Center for Geography and Regional Planning, Série Estudos; 1999. p. 211-222.
10. Douglas D, Bryant CR, Joyal A. Community Economic Development and Strategic Planning, training material produced for the Community Futures Program. Canada: Employment and Immigration Canada; 1992. $408 \mathrm{p}$.

11. Bryant CR. Community Crossroads. Design and author of the documentation for this awareness program for the population of single industry towns for the Federation of Canadian Municipalities. The documentation consists of: 1) Training Guidebook 2) Orientation Seminar Guidebook 3) How to Workshops Guidebook. 1989.

12. Bryant CR, Chahine G, Bousbaine. Local action and multi functionality at the service of the protection of the agricultural territory: crossreferencing between Quebec and France. In: Bryant CR, Loudyi S, editors. Agricultural Spaces in Metropolization. France; 2017. p. 273 296.

13. Native Plant Solutions. Wetlands and Their Benefits: Review and Synthesis of Tools and Models Assessing Wetland Functions and Ecosystem Services. Canada: A report submitted to the Alberta Biodiversity Monitoring Institute and Alberta NAMWP; 2017. p. 1-69.

14. Akkari C, Bryant CR. Toward Improved Adoption of Best Management Practices (BMPs) in the Lake Erie Basin: Perspectives from Resilience and Agricultural Innovation Literature. Agriculture. 2017;7(7):54. 